\title{
Effects of Glutamate and Aspartate on Ataxic Gait Induced by 3-Acetyl Pyridine in Rats
}

\author{
G. DE MICHELE. F.B. JOLICOEUR, D.B. RONDEAU, R.F. BUTTER WORTH and A. BARBEAU
}

SUMMARY: The main purpose of this study was to examine the effects of intraventricular injections of glutamate and aspartate on the walking gait of rendered ataxic by the administration of 3-acetyl plridine. Both amino acids significantly improved the walking gait of these animals. The effects of other substances known to have a stimulatory influence on locomotor activity in rats were also investigated. Amphetamine, apomorphine and thirotropin releasing hormone (TRH) had no effect on the ataxic gait of 3-A P reated animals. Substance P significantly improved the gait of ataxic animals, but to a lesser extent than that seen with glutamate and aspartate.

RÉSUMÉ: L'objectif premier de cette étude fut d'examiner les effets d'injections intraventriculaires de glutamate et d'aspartate sur la démarche alaxique d'animaux traités à la 3-acetyl-pyridine. Une amélioration significative de la démarche fut observée suite à l'administration de ces deux acides aminés. Les effets possibles de diverses substances capables de stimuler l'activité locomotrice chez les animaux, furent également étudiés. L'amphetamine, l'apomorphine et la TRH n'eurent aucun effet sur la démarche ataxique des animaux. La substance $P$ améliora de façon significative la démarche des animaux; par contre son effet fut moins marqué que celui du glutamate et de l'aspartate.
From the Department of Neurobiology, Clinical Research Institute of Montreal.

Reprint requests for the complete supplement on Friedreich's Ataxia (phase three) to: Dr. André Barbeau, Clinical Research Institute of Montreal, 110 Pine Ave. West, Montreal, Québec, Canada H2W IR7.

\section{INTRODUCTION}

Administration of 3-acetyl pyridine (3-AP), a nicotinamide antagonist (Hicks, 1955), produces within 24 hrs, a destruction of the inferior olivary nucleus (Desclin, 1974) with a consequential loss of climbing fibers to the cerebellum (Desclin and Escubi, 1974). These histological changes resemble those observed in olivo-cerebellar atrophy (Holmes, 1907).

The two acidic amino acids, aspartate and glutamate, have been considered as possible candidates for a neurotransmitter role in the climbing fibers (Guidotti et al, 1975; Nadi et al, 1977). Levels of glutamate and aspartate in brains of 3-AP treated animals have been examined in several studies and decreased cerebellar concentrations of both amino acids have been reported (Butterworth et al, 1978; McBride et al, 1978; Rea et al, 1980). Similar decreases in aspartate and glutamate have been found in cerebellum, brain, and spinal cord of Friedreich's ataxia patients (Robinson, 1968; Huxtable et al, 1979).

The administration of 3-AP to animals produces a marked ataxic gait and other neurological signs which have been quantified and described in detail recently (Jolicoeur et al, 1979). The ataxic syndrome may be a consequence of decreased concentrations of glutamate and of aspartate in the cerebellum of 3-AP treated rats. The main purpose of this study was to examine the effects of intraventricular injections of aspartate and glutamate on ataxia induced by $3-A P$.

\section{EXPERIMENT I}

In this experiment, we examined the effects of $1.62 \mu \mathrm{m}$ of aspartate and of glutamate on both relatively mild and severe ataxic gaits which were induced by 32.5 and $65 \mathrm{mg} / \mathrm{kg} \mathrm{3-AP}$ respectively. The dose of aspartate and glutamate was selected on the basis of preliminary experiments which indicated that neither amino acid, given in this amount, produced any sign of toxicity in animals.

\section{Methods}

One hundred and eight male albino rats, 275-300 g. in weight, were used. They were implanted under pentobarbital anesthesia with an indwelling cannula (26 gauge) into the left brain ventricule. A recovery period of at least $36 \mathrm{hrs}$ was given before treatments were initiated.

On Treatment Day, animals were injected intraperitoneally with either $.9 \% \mathrm{NaCl}, 32.5 \mathrm{mg} / \mathrm{kg} \mathrm{3-AP}$ or 65 $\mathrm{mg} / \mathrm{kg}$ 3-AP. Three groups of 12 animals were assigned to each treatment. Liquid 3-AP (Sigma chemicals) was mixed with $.9 \% \mathrm{NaCl}$ to obtain an injection volume of $1 \mathrm{ml} / \mathrm{kg}$.

Twenty four hours later, on Test Day, the animal's walking gaits were measured. For that purpose, animals with their hindfeet stained with ink, were walked through an enclosed 90 $\mathrm{cm}$ long corridor with a paper covered floor. The angle between consecutive and contralateral ink marks, representing the animal's steps, was then calculated. A detailed description of this procedure has been published (Jolicoeur et al, 1979). After a first recording of walking patterns, animals were injected intraventricularly with either $.9 \%$ saline, $1.32 \mu \mathrm{m}$ glutamate, or $1.32 \mu \mathrm{m}$ aspartate. Three groups of animals, each having received a particular treatment on Treatment Day, were assigned to the various injections. Animal's gaits were measured immediately following injections as well as I hr after. Glutamate and 
aspartate were dissolved in $.9 \% \mathrm{NaCl}$ and $\mathrm{Ph}$ of solutions was adjusted with sodium hydroxide. Intraventricular injections were performed by means of $50 \mu$ l Hamilton syringe, linked to the animal's cannulas with PE-20 polyethylene tubing. Volumes of injections were $10 \mu \mathrm{l}$, given over a $30 \mathrm{sec}$. period.

\section{Results}

Data obtained with each set of three groups given a particular treatment on Treatment Day, were analysed by individual two way ANOVA's for repeated measures (Winer, 1971). Factors included in each analysis were injections and test period. Each of the three injections given on the Test Day, $.9 \% \mathrm{NaCl}$, glutamate and aspartate, constituted one level of the injection factor. Each of the gait measurements, performed before, immediately following, and $1 \mathrm{hr}$ after injections, contributed to one level of the test period factor. For the groups administered $.9 \% \mathrm{NaCl}$, the critical injection by test period interaction was significant $(\mathrm{P}<0.05)$. This interaction was examined by performing simple main effect analyses at each level of both factors and by comparing individual groups by means of Dunnett tests. These tests revealed that for the two groups injected with glutamate and aspartate, angles of gait immediately following injections were significantly larger than those measured prior to injection $(P<0.01)$. No other significant differences were found.

For the groups treated with 32.5 $\mathrm{mg} / \mathrm{kg} 3-\mathrm{AP}$, the injection by test period interaction was also significant $(\mathrm{P}<0.01)$. Follow up analyses indicated that immediately following injections, the angles of the groups injected with aspartate and glutamate were significantly increased in comparison to the group injected with .9\% $\mathrm{NaCl}(\mathrm{P}<0.01)$. Also, for both glutamate and aspartate groups, the angles following injection were significantly larger than those measured prior to injections $(\mathrm{P}<0.05)$. At the $1 \mathrm{hr}$ post injection test period, the animals injected with aspartate still displayed a significantly enlarged gait angle $(\mathrm{P}<0.01)$.

A significant injection by test period interaction was also found for the groups treated with $65 \mathrm{mg} / \mathrm{kg} \mathrm{3-AP}$ $(P<0.01)$. Subsequent analyses revealed that in comparison to the group given $.9 \% \mathrm{NaCl}$, the gait angles of both glutamate and aspartate groups were significantly increased immediately following as well as $\mathrm{I} \mathrm{hr}$ after injections $(\mathrm{P}<0.05)$.

In summary, the preceding statistical analyses indicate that both aspartate and glutamate can significantly ameliorate the walking gait of animals rendered ataxic by the administration of either 32.5 or $65 \mathrm{mg} / \mathrm{kg} \mathrm{3-AP}$. The results are illustrated in Fig. 1 where mean gait angles obtained with each group under the various experimental conditions are presented.

\section{EXPERIMENT 2}

The results of the preceding experiment indicate that both glutamate and aspartate can significantly improve the walking gait of 3-AP treated animals. In the course of the experiment, it was observed that the administration of both amino acids induced a strong forward locomotion in the animals. This effect was of short duration but was present at the time the animals" gaits were recorded. It is possible that the amelioration of walking gaits was secondary to the sudden increase in locomotor activity induced by glutamate and aspartate. Therefore, it seemed warranted to examine the effects of other substances known to increase locomotor activity in rats. In the second experiment, the effects of substance $P(S P)$, thyrotropin releasing hormone (TRH), apomorphine and amphetamine on the walking gaits of animals treated with $32.5 \mathrm{mg} / \mathrm{kg}$ 3-AP were examined.

\section{Methods}

Methods and procedures were similar to those employed in the first experiment. Twelve cannulated rats were injected with $32.5 \mathrm{mg} / \mathrm{kg} 3-\mathrm{AP}$.
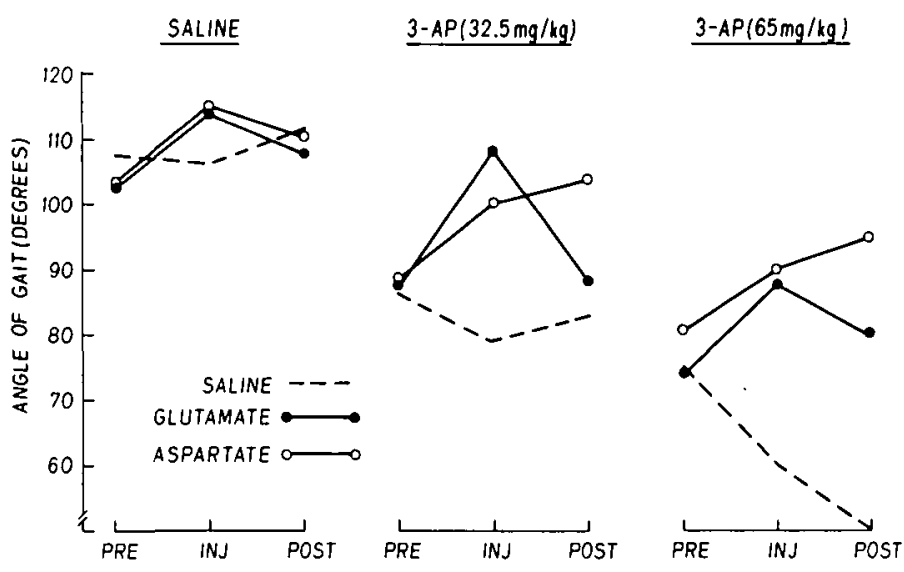

Figure 1 - Mean gait angles (in degrees) presented as a function of various treatments of experiment 1. Angles were measured immediately before (PRE) and after (INJ) injections, as well as 1 hr after (Post).

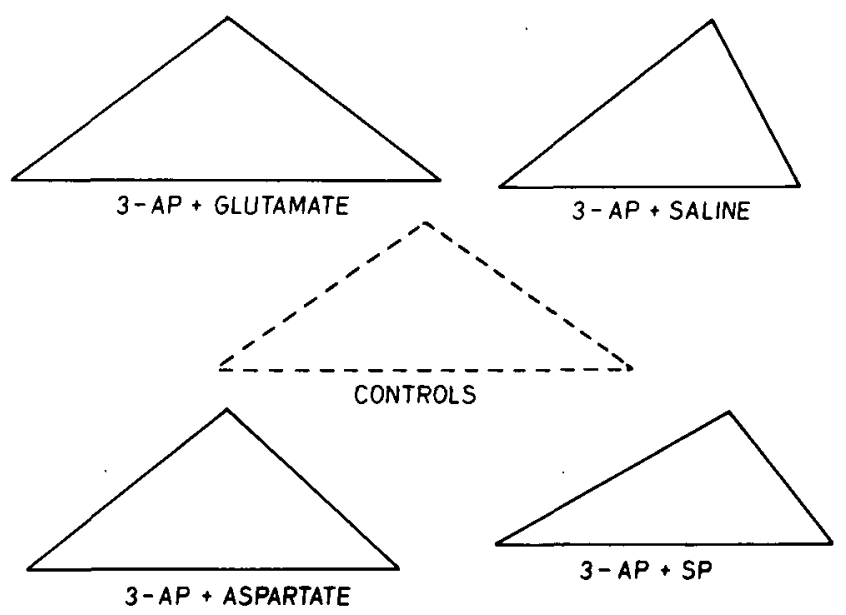

Figure 2 - Schematic representations of walking gait of experimental and control animals of Experiment 1 and 2. Experimental animals were injected acutely with $32.5 \mathrm{mg} / \mathrm{kg}$ of 3-acetyl pyridine on Treatment Day and were administered either $.9 \% \mathrm{NaCl}$, Glutamate $(1.32 \mu \mathrm{M})$, Aspartate $(1.32 \mu \mathrm{M})$ or Substance $\mathrm{P}(0.6 \mu \mathrm{g})$ on Test Day. 
TABLE 1

Means And Standard Errors Of Activity Scores And Angles Of Gait In Experiment 2

\begin{tabular}{lcccc}
\hline \multicolumn{1}{c}{ Treatment } & \multicolumn{2}{c}{ Activity } & \multicolumn{2}{c}{ Angle of gait (Degrees) } \\
& Pre-injection & Injection & Pre-injection & Injection \\
\hline Substance P & $13.2 \pm 3.2$ & $45.0 \pm 8.2^{* *}$ & $86.9 \pm 4.6$ & $101.1 \pm 4.9^{*}$ \\
TRH & $11.0 \pm 2.7$ & $91.6 \pm 9.3^{* *}$ & $85.1 \pm 5.7$ & $85.6 \pm 4.7$ \\
Apomorphine & $14.5 \pm 3.8$ & $39.0 \pm 5.6^{*}$ & $92.1 \pm 3.9$ & $74.4 \pm 5.4$ \\
Amphetamine & $10.0 \pm 3.3$ & $34.5 \pm 6.0^{*}$ & $89.6 \pm 4.3$ & $86.4 \pm 4.5$ \\
\hline P $P 0.05$ & & & & \\
* $<0.01$ & & & &
\end{tabular}

Twenty four hours later, animals received each of the following treatments in a counterbalanced order: SP $(0.6 \mu \mathrm{g})$; TRH $(10 \mu \mathrm{g})$; amphetamine $(1 \mathrm{mg} / \mathrm{kg})$ and apomorphine $(0.5$ $\mathrm{mg} / \mathrm{kg}$ ). A period of two hours was interspersed between each injection. SP and TRH were injected intraventricularly in a volume of $10 \mu \mathrm{l}$. Apomorphine and amphetamine were administered subcutaneously and intraperitoneally respectively, in volumes of $1 \mathrm{ml} / \mathrm{kg}$. All substances were dissolved in 0.9 percent $\mathrm{NaCl}$. Prior to each injection, locomotor activity was first measured for $2 \mathrm{~min}$ in a photocell apparatus, and walking gaits were recorded. Activity and gaits were then measured within $20 \mathrm{~min}$ following each injection.

\section{Results}

A preliminary variance analysis indicated that the animals' activity scores and walking gaits did not differ significantly in the test periods preceding each of the four injections. Because of this, data of all four-preinjection test period were combined for each animal.

For both activity and gait, results were analyzed by means of individual ANOVA's for repeated measures (Winer, 1971). Five levels of the factor were included in each analysis: combined pre-injection data and results obtained following each of the four injection treatments. A significant main effect for activity scores was found $(P<0.01)$. Post hoc Dunnett's test revealed that all four injection treatments significantly increased locomotor activity. For gait angles, a significant main effect was also found
$(\mathrm{P}<0.01)$. Post hoc tests indicated that the gait angles following SP administration were significantly larger than those of the pre-injection test period. The other injection treatments did not significantly affect the ataxic gait of 3-AP animals.

Results for both activity and gait, obtained in each experimental condition, are presented in Table 1. In summary, the results of this experiment indicate that, although all four injection treatments significantly increased locomotor activity of 3-AP treated rats, only SP was able to ameliorate significantly the ataxic gait of these animals.

\section{DISCUSSION}

Results of the first experiment demonstrated that glutamate and aspartate can significantly improve the walking gait of animals rendered ataxic by 3-AP. The improvement in gait was due to an enlargement of the reduced gait angle of 3-AP treated animals (Fig. 1). The enhancing effects of glutamate and aspartate on gait angles was not specific to animals administered 3-AP, since it was also seen in the saline treated animals.

The amelioration of the gait of ataxic animals by glutamate and aspartate was more pronounced in the rats treated with the smaller dose of 3-AP. As can be seen in Fig. 1, the gait angles of animals administered 32.5 $\mathrm{mg} / \mathrm{kg} \mathrm{3-AP}$ were, following injections of glutamate and aspartate, comparable to those of saline treated animals. This systematic reversal of ataxia in these animals is more clearly illustrated in Fig. 2 where triangular representations of animals' walking strides under various conditions of this study are presented. Although the effects of glutamate and aspartate on ataxic gaits did not differ immediately after injections, it appears that the effects of aspartate were more persistent. For both doses of 3-AP, the increasing effect of aspartate on gait angles, was maintained, if not enhanced, in the $1 \mathrm{hr}$ post-injection test period (Fig. 1).

As the results of experiment 2 demonstrated, the improvement of gait in ataxic animals is not strictly the result of the observed stimulatory effect of glutamate and aspartate on locomotor activity. Apomorphine, amphetamine and TRH all increased activity, but did not affect the gait of 3-AP treated animals. The results of this experiment also indicate that the reduction in 3-AP induced ataxia is not specific to glutamate and aspartate since it was also seen following administration of SP. However the effects of this peptide were not as pronounced as those of glutamate and aspartate. As can be seen in Fig. 2, the ataxic gait pattern of 3-AP treated animals was not reversed as completely by $\mathrm{SP}$ as it was with glutamate and aspartate.

In summary, the ataxic walking gait of animals treated with 3-AP was improved markedly by glutamate, aspartate and, to a lesser extent, SP. The mechanism by which these substances exerted this effect is unknown at the present time. Whether or not the observed effects reflect a direct pharmacological action on the mechanisms underlying 3-AP induced ataxia, remains to be determined. Further studies using different animal models of ataxia and other pharmacological tools should help to delineate the specificity and the nature of the effects observed in this study.

\section{ACKNOWLEDGEMENTS}

Supported by l'Association Canadienne de l'Ataxie de Friedreich. G.D.M. is a scholar of Ministry of Health, Italy. F.B.J. is a Fellow of the Huntington Society of Canada.

\section{REFERENCES}

BUTTER WORTH, R.F., HAMEL, E., LANDREVILLE, F, and BARBEAU, A. (1978). Cerebellar ataxia produced by 3acetyl pyridine in rat. Can. J. Neurol. Sci. 5: 1331-1333. 
DESCLIN, J.C. (1971). Histological evidence supporting the inferior olive as the major source of cerebellar climbing fibers. Brain Res. 77: 365-384.

DESCLIN, J.C. and ESCUBI, J. (1974). Effects of 3-acetyl pyridine on the central nervous system of the rat, as demonstrated by silver methods. Brain Res. 77: 349-363.

GUIDOTTI, A., BIGGIO, G. and COSTA, E. (1975). 3-Acetyl pyridine: a tool to inhibit the tremor and the increase of cGMP content in cerebellar cortex elicited by harmaline. Brain Res. 96: 201-205.

HICKS, S.P. (1955). Pathologic effects of antimetabolites. Amer. J. Path. 31: 189-197.

HOLMES, G. (1907). A form of familial degeneration of cerebellum. Brain 30: 466471.

HUXTABLE, R., AZARI. J., REISINE, T., JOHNSON, P., YAMAMURA, H.I. and BARBEAU, A. (1979). Regional distribution of amino acids in Friedreich's ataxia patients. Can. J. Neurol. Sci. 6: 255-258.

JOLICOEUR, F.B., RONDEAU, D.B., HAMEL, E., BUTTER WORTH, R.F. and BARBEAU, A. (1979). Measurement of ataxia and related neurological signs in the laboratory rat. Can. J. Neurol. Sci. 6: 209215.

MCBRIDE, W.J., REA, M.A. and NADI, N.S. (1978). Effects of 3-acetyl pyridine on the levels of several amino acids in different CNS regions of the rat. Neurochem. Res. 3: 793801.

NADI, N.S., KANTER, D., MCBRIDE, W.J. and APRISON, M.H. (1977). Effects of 3-acetyl pyridine on several putative neurotransmitter amino acids in the cerebellum and medulla of the rat. J. Neurochem. 28: $661-662$.

REA, M.A., MCBRIDE, W.J. and ROHDE, B.H. (1980). Regional and synaptosomal levels of a mino acid neurotransmitters in the 3-acetyl pyridine deafferentated rat cerebellum. J. Neurochem. 34: 1104-1106.

ROBINSON, N. (1968). Chemical changes in spinal cord in Friedreich's ataxia and motor neurone disease. J. Neurol. Neurosurg. Psychiat. 31: 330-333. 